\title{
CURTO-CIRCUITO, FALTA DE LINHA OU NA LINHA? REDES DE ENFRENTAMENTO À VIOLÊNCIA CONTRA MULHERES EM SÃO PAULO
}

\author{
Cecília MacDowell Santos \\ Universidade de São Francisco (Califórnia)
}

\begin{abstract}
Resumo: Este artigo examina as abordagens das/os agentes do Estado sobre violência doméstica e os fatores que condicionam a aplicação da Lei Maria da Penha no que se refere às diretivas para a constituição e expansão de serviços criminais e não criminais a serem integrados em uma "Rede de Enfrentamento à Violência contra Mulheres". Com base em uma pesquisa de campo realizada na cidade de São Paulo entre 2012 e 2014, o artigo mostra que, além das delegacias da mulher criadas nos anos 1980 e 1990, surgiram, na última década, novos serviços não criminais nas periferias da cidade, contribuindo para a expansão da Rede. No entanto, há várias redes, não apenas uma, as quais ora se cruzam e se alinham numa mesma abordagem sobre violência, ora se acham em conflito, ora funcionam em paralelo. As/os agentes do Estado abraçam diversas abordagens sobre violência doméstica contra mulheres, que variam entre uma perspectiva familista e perspectivas de gênero, feminista e interseccional de gênero, raça e classe social. Esta diversidade ilustra a heterogeneidade da cultura jurídicopolítica do Estado em relação aos direitos das mulheres, um Estado que caracterizo como "bipolar", regulado, por um lado, pelo regime de gênero/mulher nas políticas para mulheres, e, por outro lado, pelo regime de família na assistência social e na segurança pública. Além do contexto político, três fatores contribuem para a heterogeneidade do Estado: o vínculo institucional dos serviços; o tipo de formação das/os agentes do Estado; a história dos serviços e suas relações com a comunidade local e com os movimentos sociais.
\end{abstract}

Palavras-chave: Lei Maria da Penha; redes de enfrentamento à violência contra mulheres; Estado; violência doméstica; feminismos.

\section{Introdução}

Até o início da década de 2000, o Brasil contava com uma política de "combate" à violência contra mulheres centrada nas delegacias da mulher e nas casas-abrigo. Esta

Copyright $\odot 2015$ by Revista Estudos Feministas. 
política privilegiava a responsabilização penal, na área da segurança pública, e a assistência social a mulheres em situação-limite de risco de vida. Tratava-se de uma política fragmentada, sem um órgão federal dotado de recursos e poderes para executá-la. Em 2003, foi criada, pelo governo Lula (2003-2006 e 2007-2010), a Secretaria de Políticas para Mulheres (SPM), com status ministerial, que inaugurou uma nova política para além do "combate" à violência (na esfera criminal) e para além do Estado. A nova política de "enfrentamento à violência contra a mulher", que teve continuidade no governo de Dilma Rousseff, a partir de 2011 , incorporou a antiga demanda feminista por "atenção integral" à mulher em situação de violência, e seguiu as diretrizes da Convenção Interamericana para Prevenir, Punir e Erradicar a Violência contra a Mulher (Convenção de Belém do Pará), ratificada pelo Brasil em 1995.

Esta nova política baseia-se em um paradigma de "rede" e de "transversalidade de gênero". Promove a criação de uma "rede de enfrentamento" à violência contra a mulher que inclui instituições e serviços governamentais e não governamentais, bem como a comunidade. A "rede de atendimento", por sua vez, faz parte da "rede de enfrentamento" e inclui serviços governamentais e não governamentais cujas ações setoriais devem ser articuladas e integradas, com enfoque nas áreas de saúde, segurança pública, justiça, assistência social e educação. ' A Lei n 1 1.340/2006, conhecida como Lei Maria da Penha, determina que sejam promovidas "medidas integradas" de assistência à mulher em situação de violência doméstica e familiar, incluindo ações governamentais e não governamentais (Capítulos I e II). O Pacto Nacional pelo Enfrentamento à Violência Contra a Mulher, lançado pela SPM em 2007, e os atuais Pacto e Política Nacional de Enfrentamento à Violência contra as Mulheres incentivam, entre outras metas, a constituição, a ampliação e o fortalecimento da rede de atendimento e enfrentamento à violência contra mulheres. ${ }^{2}$

Em decorrência desta nova política nacional, a última década foi marcada pela expansão de novos serviços sobretudo na área da assistência social, a exemplo dos centros de referência de atendimento às mulheres em situação de violência, que prestam assistência psicológica, social e orientação jurídica. Estes serviços são muitas vezes criados por meio de convênio entre o Estado e organizações não governamentais (ONGs). Mas nem sempre estão subordinados às diretrizes da SPM e dos órgãos de gestão estaduais e municipais encarregados da promoção das políticas de gênero e dos direitos das mulheres. Não raro estão vinculados aos órgãos de gestão das políticas de assistência social, que centralizam na "família" - não nos direitos das mulheres ou na desigualdade de gênero - a concepção e a implementação dos seus serviços, programas e projetos. ${ }^{3}$

Confrontando esses dois setores do Estado - o da assistência social e o das políticas para as mulheres -, torna-se evidente o dualismo jurídico-político do Estado brasileiro em matéria de políticas de enfretamento à violência contra mulheres. Esta bipolaridade é semelhante à que observei no caso das políticas indigenistas e dos direitos dos povos indígenas. Neste caso, ocorre uma situação de dualismo jurídico e "Estado bipolar", onde diferentes ou os mesmos setores do Estado realizam ações contraditórias, de euforia e de depressão, para usar a metáfora bipolar, construindo e sedimentando culturas jurídicopolíticas antagônicas e irreconciliáveis. ${ }^{4}$ Esta situação corresponde a uma espécie daquilo que Boaventura de Sousa Santos ${ }^{5}$ designa por "Estado heterogêneo", em que

1 BRASIL, $2011 \mathrm{a}$.

${ }^{2}$ BRASIL, $2011 \mathrm{a}, 2011 \mathrm{~b}$ e 2013.

${ }^{3}$ BRASIL, 2005, p. 17.

${ }^{4}$ Cecília MacDowell SANTOS, no prelo.

${ }^{5}$ Boaventura de SOUSA SANTOS, 2003 , p. 56.

578 Estudos Feministas, Florianópolis, 23(2): 577-600, maio-agosto/2015 
[...] diferentes sectores da actividade estatal assumem lógicas de desenvolvimento e ritmos diferentes, sendo cada vez mais frequentes as desconexões e incongruências na actuação estatal, ao ponto de, por vezes, deixar de ser possível identificar um padrão coerente para essa actuação.

Mas será que a percepção das/os agentes institucionais sobre o problema da violência doméstica contra mulheres depende das diretrizes dos órgãos de formulação e gestão de políticas a que os serviços se vinculam, quer no âmbito federal, estadual ou municipal? ${ }^{6}$ Será que o vínculo institucional dos serviços faz alguma diferença para a constituição da "rede de enfrentamento à violência contra mulheres" (doravante citada como Rede)? Quando visitamos uma cidade e procuramos conhecer a Rede, as publicações da SPM e os guias de serviços locais podem ajudar a mapear tais serviços. Mas não dão conta da diversidade das práticas e ideologias das/os agentes institucionais ou das transformações por que passam os serviços, que muitas vezes são extintos ou modificados devido à vontade do partido político que se encontra no poder. Torna-se, assim, relevante, tanto para a ação política como para a reflexão feminista sobre o Estado, investigar, em cada localidade e em cada espaço institucional, a constituição da Rede e a ideologia das/os suas/seus agentes. Há uma ou várias Redes? Quem faz parte da(s) Rede(s)? Como as/os agentes institucionais se veem na(s) Rede(s) e se comunicam entre si? Quais as abordagens sobre violência doméstica contra mulheres adotadas pelas/os agentes que prestam serviços no âmbito da(s) Rede(s)? Defendem uma visão de proteção da "família" ou de proteção da "mulher"? Veem a violência numa perspectiva de gênero? Abordam a violência e o seu contexto numa perspectiva interseccional de gênero, raça/cor, classe social e orientação sexual?

Este artigo 7 procura dar resposta a estas perguntas, tomando como ponto de partida a relação entre as delegacias da mulher na cidade de São Paulo e os centros de atendimento à mulher em situação de violência que se vinculam à assistência social. Pretende-se examinar a relação entre as/os agentes desses serviços, a forma como participam na constituição da(s) Rede(s), e refletir sobre as suas abordagens da violência doméstica contra mulheres. Assim, o objeto desta análise não é o "atendimento em rede", o funcionamento dos serviços em conformidade ou não com a Lei Maria da Penha e com as diretrizes da SPM, senão a constituição da(s) "rede(s) de atendimento" e as ideologias das/ os suas/seus agentes. Além disso, o nível da análise é local (municipal e estadual), ainda que forças extralocais (nacionais e regionais) possam ser relevantes para se compreender as relações entre atores locais e as suas ideologias. ${ }^{8}$

A partir da pesquisa que realizei na cidade de São Paulo nos meses de julho e agosto de 2012, maio de 2013 e fevereiro até abril de 2014, incluindo entrevistas e visitas a diferentes espaços institucionais que se dedicam ao enfrentamento da violência doméstica

\footnotetext{
" Utilizo o termo "agentes institucionais" em referência aos indivíduos que trabalham nas instituições. As instituições, por sua vez, são "atores" vinculados direta ou indiretamente ao Estado.

7 Uma versão preliminar deste texto foi apresentada no XXXII Congresso Internacional da Latin American Studies Association, realizado em Chicago entre 21 e 24 de maio de 2014. Agradeço a Mikaela Rowland, Teresa Henriques, Wagner Pereira e Sonia Coelho pelos comentários para aprimorar o texto. Sou grata a Carlos MacDowell e Ana Reis pela hospitalidade durante a pesquisa de campo em São Paulo. Agradeço também a Carolina Cutrupi pela assistência na pesquisa, bem como a Cynthia Portela e Guilherme Meireles pela transcrição de entrevistas. Agradeço especialmente a todas/os que me concederam entrevistas, documentos e acolheram-me em suas instituições. Esta pesquisa contou com o apoio do Faculty Development Fund da University of San Francisco e contribui para o Projeto Alice "Strange Mirrors, Unsuspected Lessons", no Centro de Estudos Sociais da Universidade de Coimbra.

${ }^{8}$ Ver, por exemplo, a análise de Elisabeth Jay FRIEDMAN (2009) sobre a importância do espaço regional, como a Organização dos Estados Americanos, para o estabelecimento de normas regionais e nacionais relativas ao enfrentamento da violência doméstica contra mulheres na América Latina.
} 
contra mulheres, identifiquei diferentes abordagens sobre este tipo de violência, que podem ser denominadas de familista, feminista, de gênero e interseccional de gênero/raça/classe. Confirmando resultados de outras pesquisas realizadas em São Paulo e em outras cidades, observei a existência de várias redes e diversos graus de articulação entre os serviços. ${ }^{9}$ Além disso, verifiquei que a relação entre as/os agentes dos serviços caracteriza-se ora pela existência de conflitos de abordagens sobre violência doméstica contra mulheres (o que chamo de curto-circuitos), ora pela falta de comunicação entre as/os agentes ou falta de conhecimento recíproco (o que denomino de falta de linha), ora por uma boa comunicação e comunhão de abordagem da violência (o que chamo de na linha).

Diversos fatores podem explicar as diferenças entre as abordagens e os graus de comunicação entre as/os agentes dos serviços que integram as Redes. Com base nos dados recolhidos, considero que os principais fatores explicativos são os seguintes: 1) a posição institucional de cada serviço; 2) a formação profissional e extra-curricular das/os agentes institucionais; 3) a história do serviço. A seguir, situo este argumento no âmbito de estudos sobre as delegacias da mulher e as redes de enfrentamento à violência contra mulheres. Passo, então, a examinar as abordagens sobre violência que identifiquei nas delegacias da mulher e nos centros de atendimento a mulheres que visitei em São Paulo, examinando, também, a forma como têm-se constituído redes paralelas e cruzadas de enfrentamento à violência doméstica contra mulheres nesta cidade.

\section{Estudos sobre delegacias da mulher e redes de enfrentamento à violência contra mulheres}

A primeira delegacia da mulher foi criada em agosto de 1985 na cidade de São Paulo, num contexto de redemocratização política e de intensas mobilizações feministas pelo reconhecimento dos direitos das mulheres. A ideia desta delegacia foi do então secretário de segurança pública do estado de São Paulo, Michel Temer, durante o governo de Franco Montoro (1983-1987). Os movimentos de mulheres e as feministas que integravam o Conselho Estadual da Condição Feminina (CECF), criado em 1982, apoiaram a proposta de Temer. Mas a demanda feminista era pela criação de "serviços integrados" para dar conta da complexidade da questão da violência doméstica, com enfoque tanto na segurança pública, como na assistência psicológica, jurídica e social. ${ }^{10}$

Referidas pelo acrônimo DDM em São Paulo ou DEAM no país, desde então foram criadas centenas de delegacias da mulher no Brasil, embora a maior parte concentre-se na Região Sudeste. Conforme o relatório final da Comissão Parlamentar Mista de Inquérito (CPMI), instaurada no Congresso Nacional para apurar a situação de violência contra mulheres no país, contavam-se 408 DEAMs em 2012. "' De acordo com dados da SPM, entre 2003 e 2011 , houve um crescimento de $161,75 \%$ de todos os serviços especializados no atendimento à mulher em situação de violência. ${ }^{12}$ Nesse período, o serviço especializado que mais se multiplicou foi o dos centros de referência de atendimento à mulher, passando de 36, em 2003, para 187, em 2011 . A CPMl indicou a existência de 202 centros de referência em 2012, superando o número de casas-abrigo, num total de $71 .{ }^{13} \mathrm{Em}$ suma, em 2012 , as

9 Maria Filomena GREGORI, 2006; Wânia PASINATO, 2006 e 2009; Leila Linhares BARSTED e Jacqueline PITANGUY, 2013.

${ }^{10}$ Para mais detalhes sobre a criação das delegacias da mulher em São Paulo e a relação entre estas e os movimentos de mulheres nos anos de 1985 até 2003, ver SANTOS, 2005.

$"$ BRASIL, 2013, p. 47.

${ }^{12}$ BRASIL, 2011 b, p. 17

${ }^{13}$ BRASIL, 2013, p. 47 
delegacias da mulher (408) e os centros de referência (202) eram, dentre os serviços especializados, os de maior número no país.

Todos os 26 estados da Federação e o Distrito Federal assinaram o Pacto Nacional de Enfrentamento à Violência contra as Mulheres. Cada estado tem pelo menos uma delegacia especializada no atendimento à mulher. As delegacias da mulher pertencem à estrutura da Polícia Civil (polícia judiciária), órgão integrante do Sistema de Segurança Pública de cada estado. O estado de São Paulo, com uma população de cerca de 41 milhões de habitantes em 2010, ${ }^{14}$ concentra o maior número de delegacias da mulher do país, embora tenha reduzido este número nos últimos anos. Em 2008, havia 125 DDMs no estado de São Paulo. ${ }^{15}$ Até 11 de novembro de 2014, a SPM indicava um total de 120 DDMs neste estado. ${ }^{16}$

Há diversos estudos sobre as delegacias da mulher no Brasil, examinando diferentes aspectos desta instituição: a relação entre policiais e mulheres que prestam queixas; ${ }^{17} \mathrm{a}$ estrutura e o desempenho das delegacias; ${ }^{18}$ a identidade e a cultura jurídica das policiais; ${ }^{19}$ os modelos de resolução de conflitos; ${ }^{20}$ as representações da violência de gênero; ${ }^{21}$ a relação das delegacias da mulher com segmentos dos movimentos de mulheres; ${ }^{22}$ a relação entre as delegacias da mulher e outras instituições que atuam na proteção dos direitos da mulher em situação de violência. ${ }^{23}$

A partir de meados da década de 2000 , o novo marco da política nacional de enfrentamento à violência contra mulheres e da Lei Maria da Penha estimulou uma série de pesquisas sobre a aplicação desta lei, sancionada em agosto de 2006. Algumas dessas novas pesquisas têm como enfoque específico o mapeamento e o funcionamento dos serviços da rede que enfrentam a violência e atendem mulheres, dando ênfase sobretudo aos serviços nas áreas de justiça, como os Juizados de Violência Doméstica e Familiar (JVD), e de segurança pública, como as delegacias da mulher. ${ }^{24}$ Essas pesquisas apresentam, detalhadamente, a estrutura dos serviços, o perfil e o funcionamento de cada instituição, e procuram verificar se os serviços ilustram ou não "boas práticas", se atuam de maneira integrada (em rede), de acordo ou não com a Lei Maria da Penha e com as diretrizes da Política Nacional de Enfrentamento à Violência contra Mulheres.

De modo geral, tais pesquisas apontam que há precariedade nas condições de atendimento das delegacias da mulher, dos JVD e dos demais serviços. Existem diversas redes ou "microrredes" de atendimento, que nem sempre se cruzam e que dependem mais da motivação individual de agentes dos serviços do que de uma prática institucionalizada de atendimento em rede entre setores e serviços especializados. ${ }^{25}$ As pesquisas indicam também, dentre outras limitações, a falta de especialização das/os agentes desses serviços

\footnotetext{
${ }_{14}^{4}$ Dados do censo do IBGE em 2010. Ver em: http://www.ibge.gov.br/estadosat/perfil.php?sigla=sp. Acesso em: 30 abr. 2014.

${ }^{15}$ Cecília MacDowell SANTOS, 2010.

${ }^{16}$ Ver: https://sistema3.planalto.gov.br//spmu/atendimento/atendimento_mulher.php?uf=SP. Acesso em: 11 nov. 2014.

${ }^{17}$ Elaine Reis BRANDÃO, 1998; SANTOS, 2005

${ }^{18}$ CNDM, 2001; Heleieth SAFFIOTI, 2002; Célia C. Gurgel de AMARAL, 2002.

19 Sara NELSON, 1996; SANTOS, 2004 e 2005; Sarah HAUTZINGER, 2007.

${ }^{20}$ Guita Grin DEBERT, 2006; Jacqueline MUNIZ, 1996.

${ }^{21}$ Marcella BERALDO DE OLIVEIRA, 2008.

22 SANTOS, 2004 e 2005.

${ }^{23}$ GREGORI, 2006; Elcylene LEOCÁDIO e Marlene LIBARDONI, 2006; PASINATO, 2006.

24 PASINATO, 2006, 2009 e 2010; LEOCÁDIO e LIBARDONI, 2006; OBSERVE, 2009 e 2010; BARSTED e PITANGUY, 2013.

${ }^{25}$ PASINATO, 2006.
} 
na temática específica da violência contra mulheres e na abordagem da violência a partir da perspectiva de gênero. Nesse sentido, essas pesquisas são importantes para o aprimoramento da estrutura e do funcionamento dos serviços, e para a atuação destes em redes intersetoriais.

No entanto, faltam ainda análises sobre os processos e os fatores condicionantes da constituição das redes de atendimento e de enfrentamento à violência contra mulheres. Faltam análises sobre o Estado, as ideologias das/dos suas/seus agentes e as relações entre variados setores do Estado e dos movimentos de mulheres. Um dos poucos estudos que analisa a dinâmica das relações entre organizações governamentais e não governamentais que atuam no campo da violência contra mulheres foi empreendido por Gregoriie antes da entrada em vigor da Lei Maria da Penha. Em meados da década de 2000, Gregori pesquisou as relações entre as delegacias da mulher em São Paulo e outras instituições governamentais e não governamentais que atuavam na promoção dos direitos das mulheres em situação de violência. Na época, Gregori identificou a ausência de atendimento em rede, ou o que denominou de "paralelismos institucionais". Em sua análise, um dos fatores explicativos para a falta de contato entre as delegacias e os demais serviços refere-se à subvalorização institucional das DDMs no seio da corporação policial, algo decorrente em parte de a violência contra mulheres ser vista como um crime "menor" ou não ser vista como crime. Estudos anteriores ${ }^{27}$ também apontam para a desvalorização $e$ discriminação enfrentada pelas/os policiais que trabalham nas DDMs, algo que também se confirma nas pesquisas mais recentes sobre as delegaciais da mulher. Gregori ${ }^{28}$ elenca e analisa, ainda, dois fatores adicionais: primeiro, a falta de consenso ou confusão conceitual (tanto nas práticas institucionais como nos estudos) sobre o objeto do atendimento, ora sendo referido como "violência contra a mulher", "violência doméstica" ou "violência de gênero". Em segundo lugar, a falta de consenso sobre o papel da delegacia especializada, isto é, se deve haver um serviço especializado ou universalista.

Com base nos dados recolhidos na pesquisa que realizei em São Paulo entre 2012 e 2014, argumento que, além da posição institucional dos serviços, a história de cada serviço e a experiência e trajetória profissional das/os agentes institucionais são fatores importantes a influenciar as suas abordagens sobre violência e a relação entre as instituições. A confusão conceitual sobre violência e a falta de consenso sobre a necessidade de uma delegacia especializada são um sintoma, não uma explicação, das diferenças ideológicas que afastam ou aproximam agentes institucionais. O contexto político local, estadual e nacional também é relevante, mas não é determinante das práticas e ideologias das/dos agentes institucionais. Para ilustrar este argumento, tecerei, adiante, observações sobre as DDMs e as redes que observei na Zona Sul e na Zona Leste da cidade de São Paulo. Antes de apresentar estas observações, cabe uma nota sobre os métodos e os períodos da recolha dos dados.

\section{Métodos e etapas da pesquisa de campo}

Os métodos da pesquisa de campo consistiram em entrevistas semiestruturadas, visitas e observações nas organizações selecionadas, aplicação de questionário, bem como coleta de publicações oficiais das instituições sobre os seus respectivos serviços. A recolha dos dados passou por quatro etapas temporais, que dependeram da minha

${ }^{26}$ GREGORI, 2006.

${ }^{27}$ Ver, por exemplo, NELSON, 1996; SANTOS, 2005.

${ }^{28}$ GREGORI, 2006. 
disponibilidade para viajar ao Brasil, uma vez que sou professora na Universidade de São Francisco. A primeira etapa teve lugar em julho, agosto e novembro de 2012, e fevereiro de 2013. Inicialmente, a pesquisa tinha como objetivo colher dados para revisitar e traduzir o meu livro sobre delegacias da mulher em São Paulo, publicado em 2005 nos Estados Unidos. ${ }^{29}$ Por isso, dei prioridade às delegacias da mulher, especialmente à la DDM (Centro), onde eu realizara a pesquisa anterior, bem como às mulheres que prestam queixas em DDMs e às organizações não governamentais feministas que atuam no enfrentamento à violência doméstica contra mulheres.

Nesta primeira etapa, realizei uma série de entrevistas com policiais, incluindo a coordenadora do Serviço Técnico de Apoio às Delegacias de Defesa da Mulher do Estado de São Paulo (doravante citado como Serviço Técnico) e policiais na $1^{a}$ DDM (Centro) e na $5^{a}$ DDM (Zona Leste). Visitei e entrevistei a coordenadora do Centro de Cidadania 25 de Março, situado no prédio atrás da $1^{\text {1a }}$ DDM. Visitei também a Casa Eliane de Grammont, que escolhi por tratar-se do primeiro centro de referência no Brasil. Além disso, entrevistei uma das fundadoras da entidade feminista União de Mulheres de São Paulo. Visitei o NUDEMNúcleo Especializado de Promoção e Defesa dos Direitos da Mulher da Defensoria Pública do Estado de São Paulo, onde entrevistei duas representantes deste órgão. Estas, por sua vez, levaram-me ao Juizado de Violência Doméstica no Fórum de Barra Funda, onde assistimos a uma audiência coletiva com mulheres que figuravam como vítimas em inquéritos que tramitavam naquela vara. Por fim, visitei a Academia de Polícia e entrevistei professoras que dão aulas às/aos policiais que ingressam na carreira.

A segunda etapa da pesquisa ocorreu a distância e tinha como enfoque coletar dados sobre a formação das policiais e sobre as percepções das mulheres que prestam queixas em DDMs. Para realizar esta etapa da pesquisa, contratei uma assistente residente em São Paulo. Com base no roteiro que preparei, esta assistente entrevistou doze mulheres em novembro de 2012 (seis no Centro 25 de Março e seis na Casa Eliane de Grammont). Em fevereiro de 2013 , ela distribuiu e recolheu um questionário que preparei, a ser preenchido por policiais nas nove DDMs da cidade de São Paulo.

A terceira etapa da pesquisa ocorreu em maio de 2013. Eu dispunha de apenas dez dias e procurei priorizar o trabalho realizado por ONGs. Visitei a organização não governamental Coletivo Feminista Sexualidade e Saúde, que tem um projeto dedicado ao atendimento de homens autores de violência doméstica. Realizei, também, uma segunda entrevista com a coordenadora da Casa Eliane de Grammont, pois a primeira não havia sido gravada.

Na quarta e última etapa da pesquisa, que teve lugar entre início de fevereiro e meados de abril de 2014, procurei conhecer mais de perto a "rede de enfrentamento" em uma região fora do Centro. Na Zona Leste, entrevistei representantes dos serviços e das organizações que participam nas reuniões da Rede de Prevenção e Enfrentamento da Violência contra a Mulher Zona Leste (Rede Leste). Entrevistei sete mulheres usuárias dos Centros de Defesa e Convivência da Mulher (CDCMs) que haviam prestado queixas em DDMs. Entrevistei também as delegadas titulares e uma delegada assistente nas DDMs da Zona Leste, ou seja, na $5^{a}, 7^{a}$ e $8^{a}$ DDMs. Nessas delegacias, distribuí novamente os questionários que haviam sido aplicados em 2013, porque poucas policiais tinham respondido ao primeiro questionário. Entrevistei, ainda, as promotoras dos Juizados de Violência Doméstica do Fórum de São Miguel, na Zona Leste, e a equipe do Ministério Público do Juizado de Violência Doméstica do Fórum Criminal Central de Barra Funda.

${ }^{29}$ SANTOS, 2005. 
Tive também a oportunidade de participar em uma reunião da Rede da Zona Sul, liderada pela Casa Eliane de Grammont, e visitei um CDCM localizado num distrito mais distante da Zona Sul, na periferia da cidade, cujas condições de vida são semelhantes às da periferia na Zona Leste. Além disso, retomei o contato com o Serviço Técnico e tive a oportunidade de assistir à gravação e divulgação ao vivo de um curso a distância para todas as policiais que trabalham nas DDMs no estado de São Paulo. Pude também participar em duas reuniões de grupos feministas e integrantes dos movimentos de mulheres, que tiveram como enfoque a preparação para a caminhada que se realizou no dia 8 de Março, Dia Internacional da Mulher, no centro da cidade. Participei da caminhada e em dois outros eventos organizados por ONGs feministas, entrevistando duas ativistas.

Em todas as organizações que visitei, nas entrevistas e nas reuniões das Redes da Zona Sul e da Zona Leste, procurei observar e recolher dados sobre: 1) a estrutura do serviço ou da organização; 2) sua posição institucional; 3) suas atribuições; 4) a formação das profissionais; 5) suas visões e abordagens sobre violência contra mulheres; e 6) a relação com outras organizações que supostamente fazem parte da "rede de enfrentamento à violência contra mulheres" na cidade de São Paulo. Para os fins deste artigo, apresento a seguir notas a partir de dados coletados sobretudo na última etapa da pesquisa de campo, com enfoque nos itens $2,4,5$ e 6 relativamente às DDMs e aos centros de referência $e$ CDCMs que prestam assistência social, psicológica e orientação jurídica a mulheres em situação de violência doméstica. Antes de examinar as DDMs e as Redes, indico a seguir as principais características das abordagens sobre violência doméstica contra mulheres referidas pelas entrevistadas.

\section{Abordagens feminista, familista, de gênero e interseccional de gênero, raça e classe}

A identificação de diferentes abordagens da violência doméstica contra mulheres, com enfoque feminista, familista, de gênero ou interseccional de gênero, raça/cor e classe social, surgiu no decorrer de todas as etapas da pesquisa de campo. Na entrevista realizada com a coordenadora do projeto "Promotoras Legais Populares", da União de Mulheres de São Paulo, as abordagens feminista e familista foram referidas pela entrevistada para explicar o problema de os centros de antendimento à mulher estarem vinculados às políticas de assistência social.

O que aconteceu com o Brasil? As políticas que vão enfrentar a violência contra a mulher estão formuladas pelo movimento, a SPM encampa, mas quem dá o orçamento é o Ministério do Desenvolvimento Social, que é ligado à Assistência Social, com aquela concepção familista, esse é o problema. E o dinheiro sai de lá. Por exemplo, a Casa Eliane de Grammont nasceu com concepção feminista, hoje está sofrendo vários cortes e retaliações, porque a prefeitura [em 2012, sob o governo de Kassab] quer acabar com todos os serviços que têm essa concepção feminista e passar a ser familista.

Nas entrevistas com a coordenadora da Casa Eliane de Grammont ${ }^{31}$ e com o coordenador do projeto "Grupo de Reflexão com Homens Autores de Violência contra a Mulher", do Coletivo Feminista Sexualidade e Saúde, ${ }^{32}$ as abordagens feminista, familista e

\footnotetext{
${ }^{30}$ Entrevista com a coordenadora do projeto "Promotoras Legais Populares", da União de Mulheres de São Paulo, São Paulo, 23 de julho de 2012.

${ }^{31}$ Entrevista com a coordenadora da Casa Eliane de Grammont, São Paulo, 21 de maio de 2013

${ }^{32}$ Entrevista com o coordenador do projeto "Grupo de Reflexão com Homens Autores de Violência contra a

Mulher", do Coletivo Feminista Sexualidade e Saúde, São Paulo, 20 de maio de 2013.
}

584 Estudos Feministas, Florianópolis, 23(2): 577-600, maio-agosto/2015 
de gênero foram aludidas para exemplificar as diferentes perspectivas de violência adotadas pelos serviços da Rede Sul. De acordo com os/as entrevistados/as, a perspectiva feminista concebe a violência como um problema estrutural do patriarcado, em contraste com a perspectiva familista, que entende a violência como um desvio de comportamento no seio da família ou como um problema da ordem moral e religiosa. A abordagem feminista associa as causas da violência contra mulheres à desigualdade de poder entre homens e mulheres, expresso pela dominação masculina. A intervenção feminista é, portanto, social e política, e centra-se nas "mulheres" para que elas possam transformar a sua posição de subalternidade e tornar-se sujeitos de direitos. A intervenção familista incide sobre a "família" e busca "restaurar a família".

Já a perspectiva de gênero é semelhante à feminista, mas não parte de uma visão estrutural e do patriarcado, senão de uma abordagem cultural dos papéis socialmente construídos e atribuídos aos homens e às mulheres. Considera que a dominação masculina precisa ser desconstruída, não se restringindo à mudança do papel social e cultural que coloca a mulher numa posição de subalternidade. E considera que os homens, tanto quanto as mulheres, precisam de assistência psicólogica e social para transformar as suas práticas de violência. O enfoque da intervenção política incide sobre a reconstrução tanto de feminilidades como de masculinidades. Apesar dessas diferenças, os grupos feministas de mulheres não passaram, salvo raros casos, a atuar no campo das masculinidades e continuaram a realizar o seu trabalho centrado apenas nas mulheres e numa perspectiva feminista, mesmo usando a palavra gênero e mudando o vocabulário de "violência contra mulheres" para "violência de gênero".

Por último, a perspectiva interseccional da violência com base no gênero, raça e classe social foi referida pelas coordenadoras de dois CDCMs na Zona Leste, a saber, o CDCM Casa Viviane dos Santos ${ }^{33}$ e o CDCM Casa Anastácia. ${ }^{34}$ A psicóloga do CDCM Casa Cidinha Kopcak fez referência também à orientação sexual, além de gênero, raça/etnia e classe social. ${ }^{35} \mathrm{~A}$ abordagem interseccional da violência assemelha-se em alguns aspectos à perspectiva feminista, pois parte de uma visão estrutural de dominação das mulheres. Mas considera a intersecção entre diversos sistemas de opressão, como patriarcado, racismo e capitalismo, e também incorpora a perspectiva de gênero e a necessidade de se trabalhar com homens autores de violência.

\section{Perspectivas familista e de gênero nas Delegacias da Mulher}

A cidade de São Paulo é uma das mais populosas do mundo, com cerca de 11 milhões e 200 mil habitantes. ${ }^{36}$ O número de DDMs nessa cidade tem-se mantido estável desde a década de 1990. Contam-se nove DDMs, distribuídas pelas diferentes zonas territoriais, correspondendo às seccionais da Polícia Civil. A principal função das delegacias da mulher é investigar crimes de violência contra mulheres, incluindo, por exemplo, violência doméstica, estupro (dentro e fora das relações de intimidade), tráfico de mulheres, assédio sexual, entre outros. Desde meados dos anos 1990, as atribuições das DDMs expandiramse, passando a incluir crimes contra crianças e adolescentes, execução de mandados de prisão civil de pais por falta de pagamento de pensão alimentícia aos filhos, e novas

${ }^{33}$ Entrevista com a coordenadora da Casa Viviane dos Santos, centro de Itaquera, São Paulo, 13 de fevereiro de 2014.

${ }^{34}$ Entevista com a coordenadora da Casa Anastácia, Cidade Tiradentes, São Paulo, 24 de março de 2014.

${ }^{35}$ Entrevista com a psicóloga da Casa Cidinha Kopcak, bairro de São Mateus, São Paulo, 9 de abril de 2014.

36 IBGE, 2013. 
atribuições previstas na Lei Maria da Penha, como medidas protetivas (por exemplo, afastamento do agressor do lar), além das medidas punitivas (registro do fato criminoso em Boletim de Ocorrência-BO e instauração de inquérito policial).

Não cabe aqui examinar as atribuições das DDMs. Mas vale observar que a Lei Maria da Penha, que se restringe à violência doméstica e familiar, teve um impacto nas atribuições das delegacias da mulher, provocando um aumento de trabalho cartorário. A coordenadora do Serviço Técnico relatou-me, em abril de 2014, que estava tentando articular-se na Secretaria de Segurança Pública para reduzir as atribuições destas delegacias. ${ }^{37}$ Mas as/os policiais que entrevistei divergem sobre quais devam ser as atribuições desta instituição especializada, se deve ou não restringir-se à Lei Maria da Penha. ${ }^{38}$ Nenhuma considerou, no entanto, que a delegacia da mulher deva ser extinta. Assim, ao contrário do que observou Gregori, ${ }^{39}$ este não parece ser um fator relevante a interferir na forma como as DDMs relacionam-se com outros serviços voltados para a proteção dos direitos da mulher.

Já a posição institucional das DDMs na corporação policial tem sido problemática e ambígua desde a sua origem. E o contexto institucional e político em que se inserem as DDMs é relevante porque se reflete no tipo de formação dada às/aos policiais, o que, por sua vez, contribui para a abordagem policial sobre violência doméstica contra mulheres. A Polícia Civil não valoriza o trabalho das DDMs. Muitas policiais não desejam trabalhar nas DDMs. Este trabalho é visto como "castigo". A violência doméstica contra mulheres ainda é vista como um problema menor, em comparação com crimes de tráfico de armas, por exemplo, e nem sempre é concebida sequer como "crime". As DDMs têm, de fato, pouca força institucional e políitica no âmbito da Secretaria de Segurança Pública. O Serviço Técnico mantém uma relação de sinergia com o Conselho Estadual da Condição Feminina (CECF). Mas este órgão não tem orçamento e força política para intervir nas políiticas do estado. Desde o final da década de 1990, o CECF vem perdendo cada vez mais a legitimidade que conquistou inicialmente para representar os interesses da sociedade civil e as demandas dos movimentos de mulheres. Não há uma secretaria de políticas para mulheres no âmbito estadual, o que prejudica a articulação entre políticas nacionais, estaduais e municipais. Nos últimos doze anos, os governos do estado de São Paulo não têm investido suficientemente quer na Polícia Civil, quer nas políiticas para mulheres.

Falta na Academia de Polícia uma formação institucionalizada sobre a temática da violência contra mulheres e a Lei Maria da Penha. Assim que ingressam na carreira, todos/as os/as policiais passam por um curso preparatório na Academia de Polícia, num período que varia entre três a seis meses. O curriculum desse curso inclui uma série de aulas sobre variados ramos do direito (penal, civil, constitucional, administrativo) e aulas práticas voltadas às funções da polícia. Todas as policiais que entrevistei e as que responderam aos questionários distribuídos nas nove DDMs da cidade de São Paulo informaram que, no curso preparatório de ingresso à carreira policial, tinham assistido a apenas uma ou a nenhuma aula sobre violência contra mulheres. As que ingressaram na carreira depois de 2006 tiveram uma ou nenhuma aula sobre a Lei Maria da Penha.

Em resposta a denúncias de mau atendimento nas DDMs, encaminhadas à Corregedoria de Polícia e à SPM em novembro de 2013, a coordenadora do Serviço Técnico

\footnotetext{
${ }^{37}$ Entrevista com a coordenadora do Serviço Técnico de Apoio às Delegacias de Defesa da Mulher, São Paulo, 1 de abril de 2014

${ }^{38}$ Além da coordenadora do Serviço Técnico, entrevistei a delegada titular e cinco policiais da $1^{\mathrm{a}} \mathrm{DDM}$, em 2012; as delegadas titulares da 5a DDM, em 2012 e 2014, respectivamente; a delegada titular e a delegada assistente da $8^{\mathrm{a}} \mathrm{DDM}$, em 2014.

${ }^{39}$ GREGORI, 2006.
}

586 Estudos Feministas, Florianópolis, 23(2): 577-600, maio-agosto/2015 
propôs ao Delegado Geral de Polícia a realização de um curso à distância de "atualização" dos/as policiais que trabalham nas DDMs em todo o estado de São Paulo. O curso foi realizado no primeiro semestre de 2014 . Chamou-me à atenção a iniciativa e o empenho desta coordenadora, que enfrentou muita resistência por parte da corporação e também das/os policiais nas DDMs. ${ }^{40}$ Mas também me chamou à atenção o conteúdo do curso. Percebi que o problema não é apenas ter ou não ter curso de formação sobre violência contra mulheres e a Lei Maria da Penha. O curso a que assisti teve a duração de um dia, em 3 abril de 2014, e contou com palestrantes que lecionam na Academia de Polícia - três policiais e uma psicóloga - todas/os vinculadas/os à Polícia Civil. Não havia um/a professor/ a convidado/a, por exemplo, de outra instituição ou algum/a professor/a de estudos feministas ou de gênero, ou mesmo professoras/es feministas que lecionam direitos humanos em faculdades de Direito no estado de São Paulo. Uma das palestrantes discorreu sobre a Lei Maria da Penha e explicou diversos aspectos da lei, inclusive a definição de violência doméstica como uma violência baseada no gênero e como violação de direitos humanos. Outra palestrante abordou o tema da "justiça restaurativa" e sua aplicação na DDM. Este conteúdo do curso pareceu-me preocupante, porque o modelo de justiça restaurativa parte da ideia de "mediação" e "conciliação" com vistas à "restauração da paz". Nos casos de violência doméstica, este modelo de justiça pode levar, como acontece em muitas DDMs e como ocorria nos Juizados Especiais Criminais (JECrim), à reconciliação de casais em prejuízo da proteção dos direitos da mulher. ${ }^{41}$

Os movimentos de mulheres lutaram para retirar os crimes de violência doméstica da competência dos JECrim, o que ocorreu com o advento da Lei Maria da Penha ${ }^{42}$ Esta lei determina que sejam criados juizados especializados em violência doméstica, cumulativos das áreas cíveis e criminais. Na prática, porém, a violência doméstica nem sempre é vista como um crime. A pesquisa recente sobre delegacias da mulher e juizados de violência doméstica em quatro capitais, incluindo São Paulo, revela que "para muitos profissionais, sobretudo policiais, a violência doméstica e familiar continua a ser percebida como problema de natureza social cuja solução não deveria ser encaminhada através da intervenção policial ou do sistema de justiça criminal." ${ }^{43}$

Tenho entrevistado policiais nas DDMs da cidade de São Paulo desde meados da década de 1990 e, tal como naquela década, encontrei, nos últimos dois anos, diferentes abordagens sobre violência doméstica contra mulheres. ${ }^{44}$ Muitas policiais têm alguma familiaridade com a linguagem de "gênero", referida como uma relação "entre homem e mulher". Mas não há uma elaboração mais aprofundada sobre "gênero" e a maior parte das entrevistadas não conhecia o discurso de "violência de gênero" disseminado na Lei Maria da Penha e nos planos de governo. Embora haja uma visão mais geral de que a violência doméstica não é um crime tão grave quanto outros crimes, nem todas as policiais entrevistadas assumem uma posição "familista". Mas nenhuma chegou a identificar-se como "feminista", e todas veem o feminismo como um movimento "radical", de "mulheres contra os homens". As que se apropriam de um discurso de gênero muitas vezes veem a violência como um "desvio social" ou um "desvio moral", relacionado com o uso de drogas ou abuso de álcool. Mas há exceções, como a delegada titular da $1^{a} \mathrm{DDM}$ (Centro) e da $8^{a}$ DDM (Zona Leste), que se apropriam do discurso de gênero entendido como uma relação

\footnotetext{
${ }^{40}$ Entrevista com a coordenadora do Serviço Técnico de Apoio às Delegacias de Defesa da Mulher, São Paulo, 1 de abril de 2014.

${ }^{41}$ Carmen Hein de CAMPOS, 2001; DEBERT, 2006; BERALDO DE OLIVEIRA, 2008.

42 BARSTED, 2006; Valéria PANDJIARJIAN, 2006

${ }^{43}$ BARSTED E PITANGUY, 2013, p. 93.

44 SANTOS, 1999, 2004 e 2005.
} 
desigual de poder entre homens e mulheres. Estas abordagens das relações sociais e da forma como a violência deva ser enfrentada - não a confusão terminológica sobre o objeto do atendimento - é que podem contribuir para o tipo de relação entre as DDMs e outras instituições e serviços da rede de enfrentamento à violência contra mulheres.

\section{Falta de linha e curto-circuito nas DDMs}

As policiais não participam nas reuniões mensais que acontecem na Rede Sul e na Rede Leste, a não ser que sejam convidadas individualmente para esclarecer dúvidas. Isto significa que muitas policiais nas DDMs não se veem como parte integrante da rede de enfrentamento à violência contra mulheres. Enquanto instituição, as DDMs pouco interagem com as redes de serviços que não sejam das esferas da segurança pública e da justiça. De modo geral, há pouco conhecimento dos serviços. Algumas policiais que entrevistei na ${ }^{a}$ DDM sequer sabiam da existência de uma "rede". A delegada titular da $1^{\text {a }}$ DDM não sabia informar o nome da coordenadora do Centro de Referência 25 de Março, que fica atrás da delegacia. As duas nunca tinham-se encontrado. Os dois prédios são separados apenas por um portão, e não é necessário sequer atravessar a rua para se passar de um prédio ao outro. Uma das policiais que respondeu ao questionário que distribuí nas DDMs indicou, inclusive, em sua resposta à pergunta sobre para que serviços encaminhava as mulheres, que gostaria de receber informações sobre os serviços existentes.

$\mathrm{Na}$ época em que Gregori ${ }^{45}$ realizou a sua pesquisa havia, para além das DDMs, alguns poucos serviços governamentais e não governamentais especializados no atendimento a mulheres em situação de violência doméstica. Mas não havia uma articulação entre tais serviços, nem havia uma rede constituída em qualquer região da cidade, ao contrário do que ocorre atualmente. Não é à toa que Gregori designou esta situação por "paralelismos institucionais". Entretanto, mesmo com o surgimento de novos serviços e com a constituição de uma ou mais redes de enfrentamento à violência em diferentes regiões da cidade de São Paulo, as DDMs continuam isoladas institucionalmente. Em geral, quando encaminham as mulheres para outras instituições, as policiais indicam serviços da assistência social não especializados no atendimento à mulher e sob a gestão da Secretaria Municipal da Assistência e Desenvolvimento Social (SMADS), tais como os Centros de Referência Especializados de Assistência Social (CREAS) e os Centros de Referência de Assistência Social (CRAS), que têm como enfoque a "família". Os autores da violência em geral são encaminhados para serviços religiosos e/ou laicos voltados para a recuperação de dependentes de drogas e álcool. Nenhuma policial que respondeu ao questionário indicou que conhecia o projeto "Grupo de Reflexão com Homens", desenvolvido no Coletivo Feminista Sexualidade e Saúde. Em suma, a falta de conhecimento das "redes de enfrentamento" e mesmo das "redes de atendimento" (serviços) é comum nas DDMs, configurando uma situação que denomino de falta de linha.

Verifiquei também uma relação de conflito ou curto-circuito entre as DDMs e os demais serviços e organizações governamentais e não governamentais que integram as redes de enfrentamento à violência contra mulheres na cidade de São Paulo. Por exemplo, na Zona Leste a $7^{a}$ DDM tem sido alvo de críticas e até de protestos organizados pelas organizações que integram a Rede de Prevenção e Enfrentamento da Violência contra a Mulher da Zona Leste. Em 2013, os CDCMs da região receberam reclamações de mau atendimento nesta DDM e procuraram dialogar com a delegada titular. Mas o diálogo não teve sucesso e as mulheres que prestam queixas nesta DDM e que são também usuárias dos

${ }^{45}$ GREGORI, 2006. 
CDCMs continuaram a reclamar do atendimento policial. Em novembro de 2013, durante as ações de mobilização da campanha mundial " 16 Dias de Ativismo pelo Fim da Violência contra as Mulheres", integrantes dos órgãos e dos segmentos dos movimentos de mulheres envolvidos na Rede Leste fizeram um protesto em frente à $7^{a} \mathrm{DDM}$ e entregaram uma cartadenúncia à delegada titular. Outra carta foi também enviada à Corregedoria da Polícia, assinada pela Marcha Mundial de Mulheres, um segmento dos movimentos de mulheres que mantém relação de proximidade com diversos serviços da Rede Leste. A delegada titular encaminhou resposta à Corregedoria no início de abril de 2014, alegando que não havia motivos para reclamações sobre o atendimento na 7a DDM.

A Zona Leste é uma área muito extensa, que inclui doze distritos policiais e três DDMs. As DDMs estão sobrecarregadas de serviço. A $7^{a}$ DDM localiza-se no centro do bairro de Itaquera, a 40 minutos de ônibus da única estação de metrô de Itaquera. Este subdistrito reúne segmentos sociais diversos e contrastantes, desde uma classe média ascendente até um elevado número de favelas e conjuntos habitacionais em estado precário. Itaquera tem passado por transformações econômicas, políticas e sociais em função das obras do estádio de futebol construído para inaugurar a Copa do Mundo de 2014. O estádio fica ao lado da estação do metrô de Itaquera, que tem acesso direto para um Shopping Center construído recentemente e que já foi palco de manifestações de jovens consumidores da região.

Visitei a $7^{a}$ DDM no dia 26 de março de 2014 , ocasião em que entrevistei a delegada titular e a delegada assistente. Ambas começaram a trabalhar na $7^{a}$ DDM em agosto de 2013 e não tinham experiência anterior em delegacias da mulher. Nenhuma das duas mencionou o episódio do protesto em frente à 7a DDM que ocorrera em novembro de 2013. Quando indagada sobre os serviços de assistência social e psicológica à mulher e para onde a DDM encaminha as mulheres, a delegada titular fez um esforço para lembrar-se de algum serviço e mencionou o CDCM Casa Viviane dos Santos, que é um dos mais antigos da região, e a Casa de Isabel, uma ONG antiga que presta serviços assistencialistas às mulheres da região mas que não participa nas reuniões da Rede Leste. Referiu também que tinha começado a participar nas reuniões da "Rede Criança", que o Grupo de Atuação Especial de Enfrentamento à Violência Doméstica (GEVID) do Ministério Público no Fórum Criminal Barra Funda começou a desenvolver, voltada especificamente para crimes sexuais em que as vítimas são crianças.

Verifica-se, assim, o surgimento de uma nova rede, sendo formada por agentes institucionais no âmbito do sistema de justiça e da segurança pública. E nesse sentido pode-se falar em várias redes, não apenas em uma rede de atendimento e de enfrentamento à violência contra mulheres. Mas as/os agentes das novas redes promovidas por setores do Ministério Público e do Judiciário em regra não participam nas reuniões das redes de enfrentamento à violência constituídas sob a liderança de agentes institucionais da área de assistência social. Apenas as/os técnicos (assistentes sociais) que compõem a equipe do Ministério Público na Vara de Violência Doméstica do Fórum de Barra Funda é que participam nas reuniões das Redes Sul e Leste.

Há policiais que fogem à regra e têm uma relação de proximidade com os demais serviços especializados para além das esferas da segurança pública e da justiça. Algumas delegadas, por interesse que vai sendo despertado no trabalho na DDM, são mais abertas a uma aproximação com os CDCMs. Por exemplo, a delegada titular da $8^{a}$ DDM, vinculada à $8^{a}$ seccional de São Mateus, na Zona Leste, tem uma relação de cooperação com o CDCM Casa Cidinha Kopcak, o primeiro a ser criado nesta região, no início da década de 2000. Esta delegada também está empenhada em participar na "Rede Criança" que vem sendo criada pelo GEVID. Esta delegada titular trabalha na $8^{\circ}$ DDM desde 2001 e acredita que a delegacia da mulher desempenha um papel importante no enfrentamento à 
violência contra mulheres. Ela foi delegada assistente de uma policial que coordenou o Serviço Técnico e que the passou conhecimentos para além do saber jurídico que se pretende neutro. ${ }^{46} \mathrm{~A}$ exemplo de algumas poucas policiais que participaram no passado em cursos de capacitação na perspectiva "de gênero", promovidos pelo Coletivo Feminista Sexualidade e Saúde em parceria com o CECF, esta delegada destaca-se, assim, por desafiar a perspectiva "familista" que predomina na cultura jurídica policial.

\section{Rede Sul: na linha ou curto-circuito entre feminismo, gênero e familismo?}

Até o início da década de 2000, havia dois centros de referência de atendimento a mulheres em situação de violência (CRM) da administração direta da prefeitura de São Paulo: a Casa Eliane de Grammont, na Zona Sul, criado pela prefeita Luiza Erundina (Partido dos Trabalhadores, PT) em 1990, e o Centro de Referência da Mulher 25 de Março, criado posteriormente na região central da cidade, ao lado da $1^{a}$ DDM. Em 2003, foi criado um terceiro centro pela prefeita Marta Suplicy (PT), a Casa Brasilândia, na Zona Norte. Além destes três serviços, a prefeita Erundina, no início da década de 1990, criou o abrigo Casa Helenira Resende de Souza Nazareth. Estes centros e o abrigo eram vinculados à antiga Coordenadoria da Mulher, também criada pela prefeita Erundina, e à Secretaria de Participação e Parceria, extinta em 2013 e convertida em três secretarias, incluindo a Secretaria Municipal de Políticas para Mulheres (SMPM). A contratação das funcionárias, todas do sexo feminino, dá-se por concurso público para ingresso nas carreiras de psicóloga e assistente social. $O$ apoio jurídico oferecido pelos três centros de referência decorre de parcerias entre a Defensoria Pública e a SMPM, que deu continuidade às parcerias antes firmadas pela Secretaria de Participação e Parceria.

A Casa Eliane de Grammont e a Casa Helenira sempre tiveram uma relação de proximidade com segmentos dos movimentos de mulheres que abordavam a violência contra mulheres numa perspectiva feminista. No início dos anos 1990, o termo "gênero" foi incorporado ao vocabulário político dos movimentos de mulheres e essas instituições passaram também a utilizá-lo. As primeiras coordenadoras da Casa Eliane de Grammont atuavam nos movimentos de mulheres, identificavam-se como feministas, eram militantes e tinham fundado ou trabalhado no SOS-Mulher de São Paulo ou em ONGs feministas, como o Coletivo Feminista Sexualidade e Saúde. ${ }^{47}$ Pouco a pouco, esta ONG tem vindo a esvaziarse, com a saída das militantes para cargos de governo ou para a carreira acadêmica. A Casa Eliane de Grammont conseguiu, no entanto, sobreviver ao declínio das ONGs, que começaram a perder financiamento no final dos anos 1990. E manteve a sua linha de atuação baseada na sua experência feminista, incorporando também a linguagem de gênero. Mas as coordenadoras e funcionárias da Casa Eliane começaram a aposentar-se e os seus cargos não têm sido repostos. A coordenadora da Casa Eliane ainda permanecerá por alguns anos nesse trabalho, mas em breve a assistente social mais antiga da casa será aposentada.

Apesar das dificuldades, este centro de referência, que ainda serve de modelo em São Paulo e no Brasil, continua a se destacar. Desde o surgimento da Lei Maria da Penha, a Casa Eliane de Grammont tem servido como aglutinadora e propulsora da Rede de Enfrentamento à Violência contra Mulheres na Zona Sul de São Paulo. Organiza e sedia as

${ }^{46}$ Entrevista com a delegada titular da 8a DDM, São Paulo, 2 de abril de 2014.

${ }^{47}$ As informações que se seguem sobre a Casa Eliane de Grammont baseiam-se na entrevista com a coordenadora deste centro de referência, São Paulo, 21 de maio de 2013. 
reuniões mensais com agentes de outros serviços ou organizações não governamentais voltados para o enfrentamento da violência contra mulheres. Continua a manter estreita relação com entidades feministas históricas e ainda atuantes, como a União de Mulheres, com quem realizou, em 2013, um projeto de escrita para mulheres em situação de violência.

A Rede Sul, como é conhecida pelas participantes, não é homogênea. A coordenadora da Casa Eliane tem uma perspectiva claramente feminista e não discorda da necessidade da intervenção voltada para homens. Mas o coordenador do projeto "Grupo de Reflexão com Homens", do Coletivo Feminista Sexualidade e Saúde, parou de frequentar as reuniões da Rede Sul por considerar muito difícil a comunicação não apenas com as familistas, como também com as feministas, conforme explicou-me em entrevista. ${ }^{48}$

Além deste curto-circuito, verifiquei que nem todas as organizações abraçam sequer a perspectiva de gênero defendida pelo Coletivo Feminista e pela Casa Eliane de Grammont. Este é o caso do CDCM Casa Sofia, que participa nas reuniões da Rede Sul. Mas a história deste serviço mostra que houve uma mudança em sua orientação. A Casa Sofia foi criada em 1999 pela entidade religiosa Sociedade Santos Mártires, da Igreja Católica, no Jardim Ângela, um bairro situado na periferia da Zona Sul de São Paulo. Esta ONG surgiu da luta por creches na região e tinha, inicialmente, uma forte ligação com o movimento de mulheres. Não seguia a visão tradicional de "defesa da família", senão a corrente social da Igreja que se aliava aos movimentos sociais. A partir de 2001 , tornou-se um serviço conveniado com a Secretaria Municipal de Assistência e Desenvolvimento Social (SMADS), através de um contrato renovável a cada quatro anos com a entidade religiosa à qual a Casa Sofia pertence. Assim, as funcionárias não ingressam no serviço por concurso público e não têm uma carreira estável. Até 2003, este era o único serviço na região que atendia mulheres em situação de violência.

Desde 2010, os CDCMs são regidos pela Portaria 46/2010, da SMADS, que dispõe sobre a "tipificação da rede socioassistencial do município de São Paulo e a regulação de parceria por meio de convênios". ${ }^{49}$ Nos termos do Anexo I desta portaria, o CDCM faz parte da "rede de serviços socioassistenciais" e caracteriza-se por "oferecer proteção e apoio a mulheres (e seus familiares) em razão da violência doméstica e familiar, causadora de lesão, sofrimento físico, sexual, psicológico ou dano moral." O objetivo geral do CDCM é "acolher as mulheres em situação de violência, oferecendo atendimento psicossocial, orientações e encaminhamento jurídico necessário à superação da situação de violência, contribuindo para o fortalecimento da mulher e o resgate de sua cidadania." Por "acolher" não se entenda alojar a mulher no CDCM, senão atendê-la com atenção, escutá-la e prestar os serviços acima descritos. O objetivo de "superação da situação de violência" e de "fortalecimento da mulher" coaduna-se com as diretrizes da Política de Enfrentamento da Violência contra a Mulher da SPM. Mas as diretrizes da Portaria 46/2010/SMADS, com enfoque na "família", demonstram uma situação de dualismo jurídico-político em matéria de políticas de enfrentamento à violência contra mulheres. Com efeito, o primeiro objetivo do CDCM, tal descrito no Anexo I desta portaria, é o de "contribuir para o fortalecimento da família no desempenho de sua função protetiva."

Em 18 fevereiro de 2014, visitei a Casa Sofia e entrevistei duas funcionárias - uma psicóloga e outra assistente social - que se referiram à filosofia da Casa Sofia em conformidade com as objetivos específicos previstos na Portaria 46/2010/SMADS. As entrevistadas explicaram que a Casa Sofia procura "restaurar a família". Na visão delas, o

${ }^{48}$ Entrevista com o coordenador do "Grupo de Reflexão com Homens Autores de Violência contra a Mulher", Coletivo Feminista Sexualidade e Saúde, São Paulo, 20 de maio de 2013.

${ }^{49}$ SÃO PAULO, 2010, Anexo 1. 
feminismo "condena o homem e quer a separação do casal". Por isso, "a filosofia da Casa Sofia não é feminista". Segundo as entrevistadas, os grupos feministas não querem "restaurar a família". Focalizam o seu trabalho apenas nos "direitos das mulheres". A Casa Sofia, ao contrário dos grupos feministas, "defende um humanismo, vendo o homem como agressor e vítima, um doente que tem que ser punido mas que precisa também de um serviço especializado". ${ }^{50}$ Apesar de a Casa Sofia ser um serviço especializado no atendimento a mulheres em situação de violência, as entrevistadas me contaram que atendem homens na Casa Sofia.

A mudança de orientação da Casa Sofia deve ser compreendida tendo em vista o contexto institucional e político local no qual se situam os CDCMs. Esta mudança parece depender de diversos fatores, como o controle local do CRAS e a falta de transmissão da história e da visão original da organização às novas funcionárias. As entrevistadas têm experiência de trabalho na entidade religiosa Sociedade Santos Mártires desde 2002 e 2008, respectivamente. Começaram a trabalhar na Casa Sofia em 2011 e 2012. Ambas participam nas reuniões da Rede Sul que acontecem mensalmente na Casa Eliane de Grammont. Mas a participação nessa Rede não supre a necessidade de formação das profissionais e a transmissão da história da organização às novas funcionárias, algo que está ausente na Casa Sofia. Como não existe uma formação institucionalizada em nenhuma secretaria ao nível municipal, estadual ou federal, as abordagens da violência por parte das funcionárias dos CDCMs, tal como acontece nas DDMs, ficam sujeitas à formação por iniciativa individual, à transmissão da história da organização ou ao poder de influência de outras organizações governamentais e não governamentais locais.

O vínculo com a SMADS e o controle local do CRAS, com seu enfoque no fortalecimento da família, pode influenciar a filosofia dos CDCMs, como acontece na Casa Sofia. A supervisão dos CDCMs é feita pelo CRAS e não se pauta pela Lei Maria da Penha e pelas políticas de enfrentamento à violência estabelecidas pela SPM. Já os centros de referência sob a gestão da SMPM, como a Casa Eliane de Grammont, recebem supervisão da SMPM, a qual, por sua vez, articula-se com, e segue, as diretrizes da SPM no âmbito federal. Mas o vínculo institucional dos CDCMs com a SMADS não é um fator determinante da filosofia desses serviços, como se verá a seguir no caso da Rede Leste.

\section{Rede Leste entre a cruz e a espada: feminismo, gênero e interseccionalidade de gênero, raça e classe}

Interessei-me por conhecer os serviços da Zona Leste a partir dos comentários feitos pela coordenadora da Casa Eliane de Grammont e pelos integrantes do projeto "Grupo de Reflexão com Homens", do Coletivo Feminista, a respeito dos novos CDCMs criados desde 2012 na Zona Leste da cidade. Eles comentaram que se tratava de centros ligados à Igreja Católica e disseram-me que esses centros tinham uma postura "familista" perante a violência doméstica contra mulheres. Depois de visitar e entrevistar coordenadoras e funcionárias de vários CDCMs na Zona Leste, descobri que este retrato não representava a diversidade de abordagens sobre violência também presentes nesta região.

Até o início da década de 2000, não havia nenhum serviço (governamental ou não) especializado no atendimento a mulheres em situação de violência na Zona Leste de São Paulo. Entre 2002 e 2004, foram criados dois CDCMs. Quase uma década mais tarde e em apenas dois anos (2012 e 2013), foram criados seis CDCMs, o triplo do que existia até então. São serviços da administração indireta da prefeitura, todos pertencentes a entidades

${ }^{50}$ Entrevista coletiva com a psicóloga e a assistente social da Casa Sofia, São Paulo, 18 de fevereiro de 2014. 
religiosas católicas, que firmaram convênios, renováveis ou não a cada quatro anos, com a Secretaria Municipal de Assistência e Desenvolvimento Social (SMADS).

Tal como a Casa Sofia, na Zona Sul, a estrutura e as funções dos CDCMs da Zona Leste regem-se pela Portaria 46/2010 da SMADS. Todos os CDCMs desta região pertencem a alguma entidade religiosa. A origem de quase todas as organizações também está relacionada com lutas locais de movimentos de mulheres. Todos os CDCMs, a exemplo da Casa Eliane de Grammont, se autointitulam "Casa" e batizaram a sua casa com o nome de alguma mulher cuja trajetória de vida significou uma luta pelos direitos das mulheres ou pelos direitos sociais de grupos marginalizados na região.

A exemplo da Rede Sul, existe uma "Rede de Prevenção e Enfrentamento da Violência contra a Mulher Zona Leste - São Paulo" (Rede Leste), conforme designada no seu "Guia de Serviços de Atendimento à Mulher em Situação de Violência Doméstica da Zona Leste". Este guia foi publicado pela SMPM em 2013 e é o mais completo que encontrei, indicando quase todos os serviços do gênero na região. As reuniões mensais da Rede Leste acontecem regularmente desde 2009. Nem todos os serviços que aparecem no Guia marcam presença nas reuniões mensais.

O CDCM Casa Cidinha Kopcak é um dos principais articuladores da Rede Leste e se destaca por ser o primeiro CDCM da região. Foi criado pela entidade religiosa Associação Comunitária Beneficente Padre José Machado Pereira, em setembro de 2002, no bairro de São Mateus. Cidinha Kopcak foi uma liderança feminista do movimento popular de mulheres durante os anos 1980 nessa região. Começou a militância nos movimentos populares ligados à Igreja Católica. Lutou por creches e outros serviços públicos, como acesso à água, luz, moradia, transporte. Participou em diversas organizações não governamentais, nos encontros feministas estaduais e nacionais, e na Subsecretaria Nacional de Mulheres do PT. Cidinha era irreverente e revolucionária, lutava pelos direitos das trabalhadoras de baixa renda, ao mesmo tempo em que desafiava preconceitos classistas e heterossexistas das feministas de classe média que viviam no Centro de São Paulo. Fez parte da organização não governamental Sempreviva Organização Feminista (SOF), cuja sede situava-se na Zona Leste e atualmente encontra-se em um bairro mais afluente perto do Centro, onde está sediada a direção da Marcha Mundial das Mulheres em São Paulo.

A memória de Cidinha está impressa não apenas na parede da sala de entrada da Casa que usa o seu nome. O legado dela pode ser observado na filosofia da Casa, que procura fortalecer as mulheres em situação de violência através do atendimento assistencial, psicológico e jurídico, bem como por meio de intervenções comunitárias, articulação com outros serviços e ativa participação na Rede Leste. A Casa Cidinha tem, portanto, um legado feminista que se manifesta ainda hoje em suas ações. Por exemplo, realiza projetos de geração de renda em parceria com a SOF e a Marcha Mundial das Mulheres. Cheguei a cruzar com uma das representantes da SOF e da Marcha já na minha primeira visita à Casa Cidinha. As funcionárias e, inclusive, algumas usuárias da Casa Cidinha também já fizeram o curso de Promotoras Legais Populares, promovido pela União de Mulheres de São Paulo.

Embora a origem e a visão da Casa Cidinha estejam alinhadas à abordagem feminista da violência, a coordenadora explicou-me que tem de tomar cuidado com as palavras que usa perante a entidade religiosa a que se vincula, e também precisa moderar o seu discurso perante a SMADS. ${ }^{51}$ O termo gênero é menos ameaçador do que feminismo, explicou-me. Tal como os demais CDCMs, a Casa Cidinha encontra-se numa posição institucional entre a cruz (da lgreja) e a espada (do Estado). Esta posição não é determinante

${ }^{51}$ Entrevista com a coordenadora da Casa Cidinha Kopcak, bairro de São Mateus, São Paulo, 19 de fevereiro de 2014. 
das ações da Casa Cidinha, mas limita os seus recursos, as suas funções e a expressão de sua visão feminista, que não pode ser revelada publicamente. Uma das limitações desta posição institucional refere-se à falta de acompanhamento jurídico nos CDCMs. Há advogadas nesses centros que prestam apoio e orientação jurídica, mas não representam as mulheres judicialmente e não acompanham os seus casos. Ao contrário da SMPM, a SMADS não tem um convênio com a Defensoria Pública para prestar este tipo de serviço nos CDCMs. Além disso, o fato de a SMADS focalizar na "família", não nos direitos da "mulher", influencia o discurso público da Casa Cidinha.

Para desenvolver um "serviço integrado" (em rede) de atendimento a mulheres em situação de violência, a Casa Cidinha procura dialogar e contar com a parceria de serviços vinculados a diversas instituições, incluindo a $8^{a} \mathrm{DDM}$, o distrito policial, os serviços de assistência não especializados nos direitos da mulher da SMADS, tais como CREAS e CRAS, e os serviços de saúde no hospital de São Mateus. Ou seja, a Casa Cidinha procura conhecer e interagir com várias redes no âmbito de diferentes instituições e orientações profissionais (policial, serviço social, saúde). Como explicou a coordenadora da Casa Cidinha, a questão não é saber se há uma ou mais redes, mas saber "de que rede eu preciso?"

Alguns dos novos CDCMs têm-se beneficiado da experiência dos dois CDCMs mais antigos - Casa Cidinha e Casa Viviane dos Santos. O CDCM Casa Zizi, por exemplo, criado em março de 2012 para atender as mulheres nos bairros de Sapopemba, Parque São Lucas e Vila Prudente, numa área da Zona Leste mais próxima do Centro e mais afluente do que as demais da Zona Leste, recebeu ajuda da Casa Cidinha na preparação do projeto que apresentou à SMADS. O CDCM Casa Anastácia, criado em junho de 2012, no bairro Cidade Tiradentes, um dos mais pobres da Zona Leste e mais distantes da regiấo central, recebe orientação e apoio da Casa Viviane. Embora estes CDCMs apresentem algumas diferenças no que se refere à sua origem e localidade, verificam-se alguns aspectos semelhantes nas suas abordagens e/ou estratégias de negociação com os demais serviços da Rede Leste. Por exemplo, a Casa Zizi adota uma "perspectiva de gênero" semelhante a aspectos da abordagem da Casa Cidinha e procura negociar com diversos serviços que Ihe possam ser úteis. Embora a coordenadora, a psicóloga e a assistente social da Casa Zizi não se identifiquem como "feministas" e vejam o feminismo como um movimento "radical" e "contra homens", elas não compartilham da abordagem familista. ${ }^{52}$ Pelo contrário, a coordenadora me contou que já chegou a enfrentar, com o apoio da polícia, toda uma comunidade numa favela em Sapopemba para retirar da comunidade uma mulher que corria risco de vida, levando-a para um abrigo sigiloso.

A Casa Anastácia, por sua vez, compartilha a visão da Casa Viviane a respeito da violência contra mulheres com base na perspectiva interseccional de gênero, raça e classe social. Ambas são coordenadas por mulheres que se identificam como negras e que militaram no movimento negro. A coordenadora da Casa Viviane também simpatiza com a Marcha Mundial das Mulheres. ${ }^{53}$ No entanto, esta ligação com o movimento negro e com a Marcha não remonta à origem da Casa Viviane. Esta foi criada em 2004 pela organização assistencialista AVIB-Associação de Voluntários Integrados no Brasil, ligada à Igreja Católica, no contexto da luta das mulheres contra a violência doméstica no bairro de Lajeado, na Zona Leste. Em 2003, Viviane dos Santos, moradora do local, foi assassinada. Na época, o

${ }^{52}$ Entrevista coletiva com a coordenadora, a psicóloga e a assistente social da Casa Zizi, São Paulo, 19 de março de 2014.

${ }^{53}$ Entrevista com a coordenadora da Casa Viviane dos Santos, centro de Itaquera, São Paulo, 13 de fevereiro de 2014.

594 Estudos Feministas, Florianópolis, 23(2): 577-600, maio-agosto/2015 
PT estava à frente da prefeitura e apoiou uma pesquisa na região para apurar a situação de violência contra mulheres. Foi desenvolvida a campanha "Abre os Olhos Companheira", que resultou na criação da Casa Viviane.

Tal como a Casa Sofia, a filosofia da Casa Viviane foi-se transformando ao longo do tempo. Mas, ao contrário da Casa Sofia, não foi influenciada pelo CRAS, senão pelos movimentos sociais locais. A Casa Viviane ampliou a sua visão de gênero para uma perspectiva interseccional de gênero, raça e classe social, posta em prática pelos novos movimentos de mulheres negras e de baixa renda que vivem nas áreas marginalizadas e periféricas das próprias periferias. Na falta de uma formação institucionalizada na perspectiva de gênero, verifica-se, assim, que os CDCMs podem seguir diferentes visões e abordagens da violência.

A Casa Anastácia, cujo nome homenageia a escrava Anastácia, símbolo da luta das mulheres negras pela abolição da escravatura no Brasil, pertence à mesma organização assistencialista AVIB a que se vincula a Casa Viviane. Realizei duas visitas à Casa Anastácia, situada na Cidade Tiradentes, um dos bairros mais pobres da periferia na Zona Leste. Na primeira visita, o meu itinerário começou no metrô Barra Funda, ao lado de Perdizes, um bairro afluente no outro lado da cidade. Na estação da Luz, no Centro, tomei um trem para a Zona Leste e depois um ônibus para a Cidade Tiradentes. O trajeto durou cerca de duas horas. Ao entrar na Cidade Tiradentes, chamou-me à atenção a quantidade de igrejas. Da janela do ônibus, tentei fotografar o enorme templo da Assembleia de Deus que se destacava na paisagem do bairro, rodeado por conjuntos habitacionais em estado aparentemente precário. A coordenadora da Casa Anastácia explicou que a história do bairro Cidade Tiradentes, com uma população em sua maioria identificada como negra e parda, mostra os efeitos excludentes do racismo na sociedade. ${ }^{54}$

A coordenadora, que trabalhou por três anos na Casa Viviane, foi a única entrevistada que abordou a questão da autoestima das mulheres negras e explicou como o problema do racismo permeia os obstáculos institucionais, socioeconômicos e psicológicos enfrentados pelas mulheres negras que buscam alternativas à situação de violência doméstica. A Casa Anastácia identifica a superação do racismo como parte integrante do objetivo geral, compartilhado pelos demais CDCMs que visitei, de "romper com o processo de violência" ou com o "ciclo de violência".

Falta, por fim, abordar os CDCMs da Zona Leste que podem ser identificados com uma perspectiva familista. Tentei agendar uma visita e uma entrevista na Casa de Isabel, entidade religiosa à qual se vincula o CDCM Naná Serafim. Entrei também em contato por telefone com o CDCM Casa Maria da Penha, que pertence à entidade Rede Criança. Mas o meu acesso a estas organizações foi vedado e não pude verificar se de fato ilustram a visão familista de que me falaram a coordenadora da Casa Eliane de Grammont, o coordenador do projeto "Grupo de Reflexão com Homens" e a coordenadora do projeto "Promotoras Legais Populares" da União de Mulheres de São Paulo. Suspeito de que a percepção dele e delas esteja correta. O CDCM Casa Maria da Penha, criado em 2012, raramente envia representante para as reuniões mensais da Rede Leste. E o CDCM Naná Serafim, criado em 2013, nunca marcou presença nestas reuniões.

\section{Considerações finais}

Desde 2006, ano da entrada em vigor da Lei Maria da Penha, verifica-se que os serviços da cidade de São Paulo expandiram-se e de fato incorporaram vários aspectos

${ }^{54}$ Entrevista com a coordenadora da Casa Anastácia, Cidade Tiradentes, São Paulo, 24 de março de 2014. 
das diretrizes da política nacional que se baseia no paradigma de "rede" para o enfrentamento à violência contra mulheres. Em São Paulo, os novos e os antigos serviços especializados no atendimento à mulher, sobretudo na área da assistência social, procuraram constituir redes para promover e aprimorar o atendimento e para reivindicar medidas políticas locais em consonância com a orientação da SPM. As Redes Sul e Leste são exemplos desta transformação, mostrando que o "paralelismo institucional" a que alude Gregori $i^{55}$ transformou-se em um conjunto de redes paralelas e cruzadas, na linha, com falta de linha ou em curto-circuito entre e dentro das redes. Mas de que redes estamos falando? Ao contrário de Gregori, procurei mostrar que a confusão terminológica acerca da "violência contra a mulher", "violência doméstica contra a mulher" e "violência de gênero" é apenas um sintoma das abordagens dos atores e agentes institucionais envolvidos nas redes de enfrentamento à violência contra mulheres. Procurei também demonstrar que a história de cada instituição e o seu contexto institucional e político são fatores que contribuem para a formação ideológica das/os agentes institucionais.

A área da segurança pública, em que se inserem as DDMs, continua a privilegiar uma abordagem familista da violência. Continua também fechada para um diálogo com as demais organizações (governamentais e não governamentais) que atuam no enfrentamento da violência doméstica contra mulheres. Salvo raras exceções de policiais que receberam formação esporádica das ONGs feministas, fora da Academia de Polícia, a maior parte das policiais conhece pouco das redes de serviços para além da esfera criminal. Existe maior abertura em relação ao contato com o Judiciário e com o Ministério Público, dando a impressão de que as DDMs respeitam estas instituições, que são do campo do Direito, e não valorizam as organizações que integram a área da assistência social. Além disso, as DDMs não se veem como um serviço que contribui para "romper com o ciclo de violência". O papel das DDMs é o de investigação criminal e de efetivação das medidas protetivas à mulher. Ou seja, trata-se de um papel de "combate" à violência.

Já os centros que prestam assistência social e psicológica têm como principal objetivo contribuir para o "fortalecimento das mulheres", ajudando-as a "romper com a violência". Este objetivo não se contrapõe ao da responsabilização penal. A punição, que é em geral uma expectativa dos movimentos de mulheres, pode, na visão das entrevistadas nos CDCMs da Zona Leste, ajudar as mulheres a continuar a romper com o ciclo da violência. A impunidade e o desestímulo ao registro da queixa, comum em algumas DDMs, é que contribuem para a acomodação das mulheres. Enfim, se a aproximação entre as DDMs e os CDCMs não é fácil, parece ainda mais difícil a aproximação das DDMs com os segmentos dos movimentos de mulheres que cobram das instituições a aplicação da Lei Maria da Penha.

Os CDCMs e os centros de referência da administração direta estão empenhados em constituir redes de atendimento e enfrentamento à violência contra mulheres. Há diferenças ideológicas e uma formação pouco institucionalizada nesses centros. Mas há também afinidades ideológicas e uma relação de troca, de aprendizado recíproco. A diferença entre serviços da administração direta e serviços conveniados não é decisiva para a maior ou menor proximidade ideológica entre os serviços. Estar submetido à gestão da SMPM ou da SMADS faz diferença, mas também não é um fator determinante. Nesse sentido, a metáfora do Estado bipolar aplica-se às orientações antagônicas das políticas da Assistência Social e da SPM. Mas a tradução destas políticas pelos serviços pode ou não seguir as diretrizes das políiticas públicas, para o bem e para o mal. Estar vinculado a uma entidade religiosa ou a uma organização laica tampouco determina a visão de

${ }^{55}$ GREGORI, 2006.

596 Estudos Feministas, Florianópolis, 23(2): 577-600, maio-agosto/2015 
cada serviço. Enfim, é preciso realizar uma etnografia do Estado, conhecer de perto cada organização, saber da sua história e das suas limitações e oportunidades institucionais e políticas. Estes são fatores que me parecem influenciar o surgimento e as transformações das diversas abordagens de violência contra mulheres que encontrei nas redes examinadas neste artigo.

Embora o contexto político não seja também determinante das ideologias e práticas das instituições encarregadas da aplicação das políticas públicas, não se pode negar a influência deste contexto. Atualmente, um dos principais temores da Casa Eliane de Grammont é não ter seu quadro de funcionárias renovado à medida em que as mais velhas vão-se aposentando. Ainda que a prefeitura de São Paulo tenha finalmente criado uma secretaria municipal de políticas para mulheres, a orientação da SPM tem enfatizado um novo eixo da política de enfrentamento à violência contra mulheres: promover a "autonomia" das mulheres como forma de empoderamento e prevenção à violência. Com isso, a SPM dá prioridade à geração de renda e serviços de atendimento a mulheres que não são especializados na questão da violência doméstica. Esta nova ênfase não exclui o objetivo de fortalecer e ampliar a rede de serviços a mulheres em situação de violência doméstica. Mas se faltarem recursos e vontade política para fortalecer os serviços da administração direta sob a gestão das secretarias municipais e estaduais de políticas para mulheres, os centros de referência, como a Casa Eliane de Grammont, correm o risco de um esvaziamento. A falta de investimento na formação continuada das profissionais, numa perspectiva de gênero (a feminista está fora de questão), é outro aspecto problemático nas ações governamentais. Aqui cabe a metáfora do Estado bipolar para ilustrar a atuação eufórica e depressiva da SPM e dos órgãos estaduais e municipais de promoção de políticas para mulheres. No êxtase da euforia, setores do Estado bipolar criam leis, planos e firmam pactos pelos direitos das mulheres. Mas no momento subsequente de depressão, a implementação carece de recursos ou cai nas mãos dos defensores da família, em detrimento dos direitos das mulheres.

Por fim, fica a esperança na capacidade de mobilização e na criatividade dos grupos de mulheres que lutam, em diversos espaços sociais e institucionais, pelo reconhecimento e pela garantia dos direitos das mulheres, tanto numa perspectiva feminista, como a partir de abordagens de gênero ou da interseccionalidade de gênero, raça, classe social, orientação sexual, entre outros eixos de diferenciação e desigualdade de poder. A presença das igrejas em toda parte não impede que a mobilização social floresça, como acontece na Zona Leste, e produza serviços que, embora posicionados entre a cruz e a espada, podem contribuir para o fortalecimento de mulheres que se encontram em situação de violência, ajudando-as a romper com o ciclo da violência. As pesquisas realizadas na cidade de São Paulo ou em outras cidades precisam prestar atenção ao que está acontecendo na periferia, que pode trazer lições importantes sobre estratégias de mobilização dentro e fora das redes de atendimento às mulheres em situação de violência.

\section{Referências}

AMARAL, Célia C. Gurgel de. "Violência em delegacias da mulher no Nordeste". In: CORRÊA, Mariza (Org.). Gênero e cidadania. Campinas: Pagu-Núcleo de Estudos de Gênero, Unicamp, 2002. p. 113-142.

BARSTED, Leila Linhares. "O avanço legislativo no enfrentamento da violência contra as mulheres". In: LEOCÁDIO, Elcylene; LIBARDONI, Marlene (Org.). O desafio de construir redes de atenção às mulheres em situação de violência. Brasília: Agende, 2006. p. 6589. 
BARSTED, Leila Linhares; PITANGUY, Jacqueline (Coord.). "Violência contra a mulher e acesso à justiça. Estudo comparativo sobre a aplicação da Lei Maria da Penha em cinco capitais". Relatório final. Rio de Janeiro: Cepia, 2013.

BERALDO DE OLIVEIRA, Marcella. "Da Delegacia de Defesa da Mulher ao Juizado Especial Criminal: significados da violência de gênero no fluxo processual". In: DEBERT, Guita Grin; GREGORI, Maria Filomena; BERALDO DE OLIVEIRA, Marcella (Org.). Gênero, família e gerações: Juizado Especial Criminal e Tribunal de Júri. Campinas: Pagu/Núcleo de Estudos de Gênero, Unicamp, 2008. p. 15-49.

BRANDÃO, Elaine Reis. "Violência conjugal e o recurso feminino à polícia". In: BRUSCHINI, Cristina; HOLLANDA, Heloísa Buarque (Org.). Horizontes plurais: novos estudos de gênero no Brasit. São Paulo: Editora 34, 1998. p. 51-84.

BRASIL. Ministério do Desenvolvimento Social e Combate à Fome. Secretaria Nacional de Assistência Social (2005). Política Nacional de Assistência Social-PNAS 2004. Brasília, 2005.

Presidência da República. Secretaria Especial de Políticas para Mulheres-SPM. Política Nacional de Enfrentamento à Violência contra as Mulheres. Brasília, 2011 a. . Secretaria Especial de Políticas para Mulheres-SPM. Rede Enfrentamento à Violência contra as Mulheres. Brasília, $2011 \mathrm{~b}$.

. Senado Federal. "Comissão Parlamentar Mista de Inquérito-CPMI com a finalidade de investigar a situação da violência contra a mulher no Brasil”. Relatório final. Brasília, 2013.

CAMPOS, Carmen Hein de. "Violência doméstica no espaço da lei". In: BRUSCHINI, Cristina; PINTO, Céli Regina (Org.). Tempos e lugares de gênero. São Paulo: Editora 34 e Fundação Carlos Chagas, 2001. p. 301-322.

CNDM-Conselho Nacional dos Direitos da Mulher. "Pesquisa nacional sobre as condições de funcionamento das delegacias especializadas no atendimento às mulheres". Relatório final. Brasília: Conselho Nacional dos Direitos da Mulher, 2001.

DEBERT, Guita Grin. "As Delegacias de Defesa da Mulher: judicialização das relações sociais ou politização da justiça?". In: CORRÊA, Mariza; SOUZA; Érica Renata de (Org.). Vida em família: uma perspectiva comparativa sobre 'crimes de honra'. Campinas: Pagu-Núcleo de Estudos de Gênero/Universidade Estadual de Campinas, 2006. p. 16-38.

FRIEDMAN, Elisabeth Jay. "Re(gion)alizing Women's Human Rights in Latin America". Gender \& Politics, n. 5, p. 349-375, 2009.

GREGORI, Maria Filomena. "Delegacias de Defesa da Mulher de São Paulo: paradoxos e paralelismos". In: DEBERT, Guita Grin; GREGORI, Maria Filomena; PISCITELLI, Adriana (Org.). Gênero e distribuição da justiça: as Delegacias de Defesa da Mulher e a construção das diferenças. Campinas: Pagu/Núcleo de Estudos de Gênero,Unicamp, 2006. p. 57. 87.

HAUTZINGER, Sarah. Violence in the City of Women: Police and Batterers in Bahia, Brazil. Berkeley: University of California Press, 2007.

IBGE - Instituto Brasileiro de Geografia e Estatística. Atlas do Censo Demográfico 2010. Rio de Janeiro: IBGE, 2013.

LEOCÁDIO, Elcylene; LIBARDONI, Marlene (Org.). O desafio de construir redes de atenção às mulheres em situação de violência. Brasília: Agende, 2006.

MUNIZ, Jacqueline. "Os direitos dos outros e os outros direitos: um estudo sobre a negociação de conflitos nas DEAMs/RJ". In: SOARES, Luiz Eduardo (Org.). Violência e política no Rio de Janeiro. Rio de Janeiro: ISER/Relume Dumará, 1996. p. 125-163.

NELSON, Sara. "Constructing and Negotiating Gender in Women's Police Stations in Brazil". Latin American Perspectives, v. 23, n. 1, p. 131-148, 1996. 
OBSERVE - Observatório pela Aplicação da Lei Maria da Penha. "Projeto: Construção e Implementação do Observatório da Lei 11.340/2006 - Lei Maria da Penha". Relatório preliminar de pesquisa. Salvador: Observe, 2009.

. "Condições para aplicação da Lei 11 .340/2006 (Lei Maria da Penha) nas Delegacias Especializadas de Atendimento à Mulher (DEAMs) e nos Juizados de Violência Doméstica e Familiar nas capitais e no Distrito Federal". Relatório final. Salvador: Observe, 2010.

PANDJIARJIAN, Valéria. "Balanço de 25 anos da legislação sobre a violência contra as mulheres no Brasil". In: DINIZ, Carmen Simone G.; SILVEIRA, Lenira P. da; MIRIM, Liz Andréa L. (Org.). Vinte e cinco anos de respostas brasileiras em violência contra a mulher (19802005): Alcances e limites. São Paulo: Coletivo Feminista Sexualidade e Saúde, 2006. p. 78-139.

PASINATO, Wânia. "Atendimento às mulheres em situação de violência em Belo Horizonte". In: LEOCÁDIO, Elcylene; LIBARDONI, Marlene (Org.). O desafio de construir redes de atenção às mulheres em situação de violência. Brasília: Agende, 2006. p. 131-167.

"Estudo de caso. Juizados Especiais de Violência Doméstica e Familiar contra a Mulher e a Rede de Serviços para Atendimento de Mulheres em Situação de Violência em Cuiabá, Mato Grosso". Relatório final. São Paulo: Observe, set. 2009.

. "Lei Maria da Penha: novas abordagens sobre velhas propostas. Onde avançamos?" Civitas, v. 10, n. 2, p. 216-232, 2010.

SAFFIOTI, Heleieth I. B. "Violência doméstica: questão de polícia e da sociedade". In: CORRÊA, Mariza (Org.). Gênero e cidadania. Campinas: Pagu-Núcleo de Estudos de Gênero, Unicamp, 2002. p. 59-70.

SANTOS, Cecília MacDowell. "Cidadania de gênero contraditória: queixas, crimes e direitos na Delegacia da Mulher em São Paulo". In: AMARAL JÚNIOR, Alberto do; PERRONE-MOISÉS, Cláudia (Org.). O cinquentenário da Declaração Universal dos Direitos do Homem. São Paulo: Edusp, 1999. p. 315-352.

"En-gendering the Police: Women's Police Stations and Feminism in São Paulo". Latin American Research Review, v. 39, n. 3, p. 29-55, 2004. .Women's Police Stations: Gender, Violence, and Justice in São Paulo, Brazil. New York: Palgrave Macmillan, 2005. "Da delegacia da mulher à Lei Maria da Penha: absorção/tradução de demandas feministas pelo Estado". Revista Crítica de Ciências Sociais, n. 89, p. 153-170, 2010. "Legal Dualism and Bipolar State: Challenges to Indigenous Human Rights in Brazil". Latin American Perspectives, 2015. No prelo.

SÃO PAULO (Município). Secretaria Municipal de Assistência e Desenvolvimento Social. Portaria 46/2010/SMADS. Disponível em: http://www.prefeitura.sp.gov.br/cidade/ secretarias/upload/chamadas/046_portaria_1298488134.pdf. Acesso em: 12 jan. 2014.

SOUSA SANTOS, Boaventura de. "O Estado heterogéneo e o pluralismo jurídico". In: SOUSA SANTOS, Boaventura de; TRINDADE, João Carlos (Org.). Conflito e transformação social: uma paisagem das justiças em Moçambique. Porto: Afrontamento, 2003. p. 47-95.

[Recebido em 17 de novembro de 2014 e aceito para publicação em 5 de fevereiro de 2015]

Short Circuit, No Line, or In Line? Networks Confronting Violence against Women in São Paulo

Abstract: This article examines State agents' approaches to domestic violence and the factors shaping the application of the Maria da Penha Law with respect to its provisions on the constitution and expansion of networked criminal and non-criminal services to cronfront violence against 
women, the so-called Rede de Enfrentamento à Violência contra Mulheres. Based on field research in the city of São Paulo between 2012 and 2014, the article shows that, in addition to the women's police stations established in the 1980s and 1990s, a number of non-criminal services have been created in the last decade in the periphery of the city, contributing to the expansion of the Rede. However, there are multiple redes (networks), not just one, and they run in line, in conflict, or in parallel with each other. State agents embrace diverse approaches to domestic violence against women, ranging from pro-family to gender-based, feminist, or intersectional (gender, race, and social class) perspectives. This diversity illustrates an heterogenous legal-political culture on women's rigths within the Brazilian State, which I dub a "bipolar" State, regulated, on one hand, by the gender/woman regime of the policies for women, and, on the other hand, by the family regime of the social assistance and public security sectors. In addition to the political context, three factors contribute to the heterogeneity of the State: the institutional base of the service; the type of professional training of State agents; the history of the service and its relationship with the local community and/or social movements.

Key Words: Maria da Penha Law; Networks to Confront Violence against Women; State; Domestic Violence; Feminisms.

600 Estudos Feministas, Florianópolis, 23(2): 577-600, maio-agosto/2015 